\title{
Sustainable green pretreatment approach to biomass-to-energy conversion using natural hydro-low-transition-temperature mixtures
}

\author{
Chung Loong Yiin ${ }^{\mathrm{a}}$, Armando T. Quitain ${ }^{\mathrm{b}, \mathrm{c}, *}$, Suzana Yusup ${ }^{\mathrm{a}}$, Yoshimitsu Uemura ${ }^{\mathrm{a}}$, \\ Mitsuru Sasaki ${ }^{\mathrm{d}}$, Tetsuya Kida ${ }^{\mathrm{b}}$ \\ a Biomass Processing Cluster, Centre for Biofuel and Biochemical Research, Chemical Engineering Department, Institute for Sustainable Living, Universiti Teknologi \\ PETRONAS, 32610 Seri Iskandar, Perak, Malaysia \\ ${ }^{\mathrm{b}}$ Department of Applied Chemistry and Biochemistry, Faculty of Advanced Science and Technology, Kumamoto University, 2-39-1 Kurokami, Chuo-ku, Kumamoto 860- \\ 8555, Japan \\ ${ }^{\mathrm{c}}$ College of Cross-Cultural and Multidisciplinary Studies, Kumamoto University, 2-40-1 Kurokami, Chuo-ku, Kumamoto 860-8555, Japan \\ d Institute of Pulsed Power Science, Kumamoto University, 2-39-1 Kurokami, Chuo-ku, Kumamoto 860-8555, Japan
}

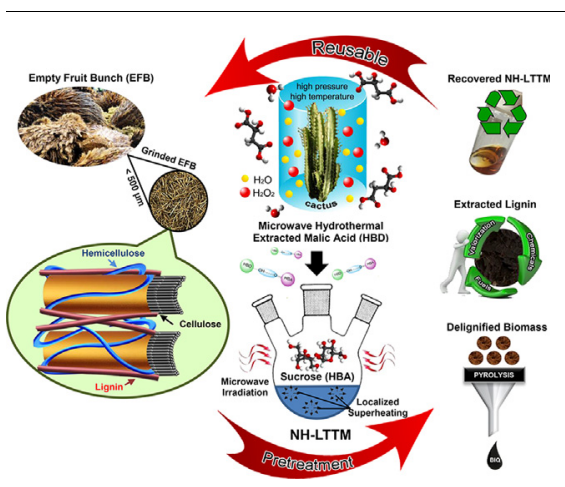

A R T I C L E I N F O

\section{Keywords:}

Microwave

Green solvent

Malic acid

Pretreatment

Biomass-to-energy

\begin{abstract}
A B S T R A C T
Natural hydro-low-transition-temperature mixtures (NH-LTTMs) tend to be the most favorable next-generation green solvents for biomass pretreatment, as they are cheap and environmental friendly. The amount of water bound into the NH-LTTMs greatly affected their thermal stability, whereby the highest thermal stability was observed with the water content of $7.6 \mathrm{wt} \%$. It is worth noting that, the highest molar transition energy of $\mathrm{NH}$ LTTMs (47.57 $\mathrm{kcal} \mathrm{mol}^{-1}$ ), which indicated the highest solubility, was optimized with the molar ratio of hydrogen bond donor (HBD)-hydrogen bond acceptor (HBA)-water (2:4:3) at a temperature of $60{ }^{\circ} \mathrm{C}$. Hydrogen bonding networks of the NH-LTTMs, which led to the dissolution of biomass, were confirmed by the alteration in the peaks of the involved bonds and resonance signal to lower field through FTIR and ${ }^{1} \mathrm{H}$ NMR spectra, respectively. The components evidenced in high-resolution mass spectra of extracted lignin showed its high potential to be valorized into useful fuels and chemicals.
\end{abstract}

\footnotetext{
* Corresponding author at: College of Cross-Cultural and Multidisciplinary Studies, Kumamoto University, 2-40-1 Kurokami, Chuo-ku, Kumamoto 860-8555, Japan.

E-mail address: quitain@kumamoto-u.ac.jp (A.T. Quitain).
} 